\title{
АНАЛИЗ ПЕРЕОСНАЩЕНИЯ АВИАЦИОННОЙ ТРАНСПОРТНОЙ СИСТЕМЫ В ТРАНСПОРТНЫЕ БЕСПИЛОТНЫЕ АВИАЦИОННЫЕ СИСТЕМЫ НА РАЗЛИЧНЫХ ЭТАПАХ ЖИЗНЕННОГО ЦИКЛА
}

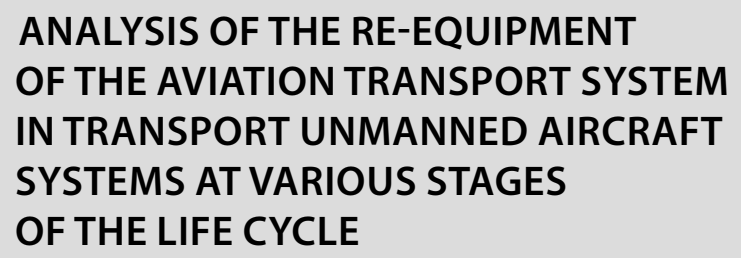

ANALYSIS OF THE RE-EQUIPMENT OF THE AVIATION TRANSPORT SYSTEM IN TRANSPORT UNMANNED AIRCRAFT SYSTEMS AT VARIOUS STAGES OF THE LIFE CYCLE

I. Salakhutdinov

Summary. The article analyzes the re-equipment of the aviation transport system in Transport unmanned aircraft systems at various stages of the life cycle. The research methodology is an analysis of the scientific literature on a given problem, as well as practical domestic experience. Special attention in the context of the issue under consideration is given to the commercial side of the issue, since it is economically more profitable to create unmanned aircraft transport systems based on existing systems. In addition, the scope of unmanned hardware has been examined, covering humanitarian operations, Internet commerce, mail service, and drug delivery. Particular emphasis is placed on the formalization of research problems that must be solved in the process of creating an unmanned aerial transport system.

Keywords: re-equipment, aviation transport system, life cycle, aviation system.

\author{
Салахутдинов Ильдар Тагирович \\ Соискатель, Инженер-конструктор, ПАО \\ «Авиационный комплекс им. С. В.Ильюшина» \\ Eleloy1@gmail.com
}

Аннотация. В статье проведен анализ переоснащения авиационной транспортной системы в Транспортные беспилотные авиационные системы на различных этапах жизненного цикла. Методология исследования анализ научной литературы по заданной проблеме, а также практический отечественный опыт. Отдельное внимание, в контексте рассматриваемой проблематики, уделено коммерческой стороне вопроса, поскольку экономически выгоднее создавать беспилотные авиационные транспортные системы на базе существующих систем. Кроме того, рассмотрена сфера применения беспилотных аппаратных средств, охватывающая гуманитарные операции, Интернет-торговлю, почтовое обслуживание, доставку медикаментов. Особый акцент сделан на формализации научно-исследовательских задач, которые должны быть решены в процессе создания беспилотной авиационной транспортной системы.

Ключевые слова: переоснащение, авиационная транспортная система, жизненный цикл, авиационная система.

антенно-фидерными устройствами для связи с мобильным командным пунктом. [1]

Этот комплекс может использоваться вместе с инфраструктурой аэродромов, вспомогательным транспортом и спутниковой системой глобального позиционирования. Беспилотная авиационная система включает в себя технический персонал и средства интеграции с другими системами, функциональные средства беспилотных авиационных комплексов, вспомогательные обеспечивающие средства, документацию и программное обеспечение для беспилотных авиационных комплексов. В составе системы представлены беспилотные летательные аппараты, в соответствии с ее целевой нагрузкой определяется ее целевое назначение. Гражданские системы чаще используются для фотосъемки, для работы такой системы кроме аппаратов требуется наземное оборудование для приема и передачи сигналов, а также для обработки полученной информации в ходе видеосъемки. [2] 
Для создания системы требуется оборудование стартовых и посадочных средств. В их составе кроме транспортных машин могут быть представлены пусковые установки с оборудованием для осуществления контроля за аппаратами перед полетом и после его завершения. Для обслуживания этой части комплекса требуется наличие технических расчетов. Для обеспечения функционирования систем требуется оборудование пунктов управления, их основой является оборудование и аппаратура, необходимые для разработки программ полетов. При помощи пунктов управления осуществляется полетный контроль, контроль в части выполнения полетных заданий, работа с информацией. Сами аппараты могут иметь стратегическое или тактическое значение. [3]

Чаще всего для управления летательными аппаратами используются стационарные пункты управления. Для подготовки летательных аппаратов к полету используются вспомогательные обеспечивающие средства. На их базе осуществляется обслуживание аппаратов после завершения полетов, проводятся ремонтные работы и хранятся средства беспилотных авиационных комплексов. Спрос на беспилотные летательные аппараты растет с каждым годом, изначально такие аппараты использовались для применения в военных целях, а также для разведки погодных данных. Самым крупным производителем беспилотных аппаратов является Китай, к 2022 г. эта страна планирует увеличить выпуск аппаратов как минимум вдвое. Всего в мире насчитывается 3200 комплексов с беспилотными летательными аппаратами. Сегодня беспилотные аппараты могут использоваться для коммерческих целей в рамках мониторинга объектов промышленной инфраструктуры. Такие же аппараты могут использоваться в целях обеспечения безопасности на границах и территориях, в рамках научных исследований для мониторинга и сбора данных по климатической обстановке и состоянию атмосферы и т.д. [4]

В течение последних лет был достигнут значительный прогресс в части производства беспилотных авиационных комплексов. Сфера их применения пока что не ограничена, исключение составляют лишь пассажирские перевозки. Основное преимущество использования беспилотных летательных аппаратов сводится к экономической эффективности. Эксплуатация таких аппаратов обходится дешевле применения спутниковых технологий для дистанционного зондирования земли. Беспилотные аппараты можно запрограммировать на следование по определенному маршруту. По данным на 2019 г., доля авиационных перевозок в России составляет $0,02 \%$ от всего объема перевозимых грузов. В среднем в странах мира эта доля составляет $2 \%$.

Беспилотные авиационные системы могут создаваться на базе существующих транспортных систем с учетом того, что уже накоплен НТЗ под разработку и производство беспилотных аппаратов. Более того, разработки и применение беспилотных аппаратов велись еще в советское время. С тех пор значительным образом увеличились возможности для более широкого использования беспилотных аппаратов за счет увеличенной грузоподъемности и других ключевых характеристик. Необходимо принимать во внимание еще один важный факт - уровень автоматизации в пилотируемой авиации, который на данный момент составляет 90\%. Создание беспилотных авиационных транспортных систем выгодно на базе существующих систем по экономическим соображениям и в связи с тем, что это позволит вывести на рынок новые сервисы и услуги для транспортных компаний. 74\% российского рынка авиационных перевозок приходится на пассажирские перевозки, на перевозку грузов приходится 17\%. В США складывается иная ситуация, при которой 68\% рынка занимают пассажирские перевозки, а перевозки грузов занимают долю 18\%. [5]

В мире сложилась успешная практика применения беспилотных воздушных судов. Сегодня они используются для участия в гуманитарных операциях и в рамках интернет-торговли, для почтового обслуживания, доставки медикаментов и т.д. Транспортные беспилотные авиационные системы могут составить конкуренцию для пилотируемых аппаратов и наземного транспорта. Беспилотные аппараты могут создаваться на базе серийных пилотируемых воздушных судов с соответствующей доработкой со стороны инженеров-конструкторов. Также в рамках создания системы могут создаваться специализированные беспилотные воздушные суда. Летательные аппараты могут быть вертолетного или самолетного типа, могут быть представлены в виде конвертопланов и воздушных судов гибридного типа. При применении беспилотных аппаратных средств стоимость летного часа можно снизить на 30\%. Даже с учетом высокого эффекта от снижения себестоимости необходимо принимать во внимание величину коммерческой загрузки беспилотных воздушных судов. [6]

Если показатели грузоподъемности сравнимы с экономической эффективностью от эксплуатации Ан-2, то она должна составлять не менее 100 кг. В сравнении с МИ-8 она должна составлять не менее 135 кг. Для трансформации существующей авиационной транспортной системы в транспортную беспилотную авиационную систему требуется создать парк из беспилотных воздушных судов, разработать транспортную (маршрутную) сеть, которая не будет мешать существующим транспортным коридорам для следования пилотируемых воздушных судов. Также требуется разработать комплекс наземных средств с целью их использования в полетном и предполетном сопровождении, создать инфраструктуру для функционирования системы, внедрить систе- 


\section{Таблица 1}

\begin{tabular}{|c|c|}
\hline $\begin{array}{l}\text { № научно-исследователь- } \\
\text { ской задачи }\end{array}$ & Описание научно-исследовательской задачи \\
\hline 2. & Выявление путей и направлений для создания беспилотных воздушных средств \\
\hline 4. & $\begin{array}{l}\text { Подготовка рекомендаций по схемам создания беспилотных летательных аппаратов с учетом } \\
\text { требования по дальности применения, характеристик грузоподъемности и т.д. }\end{array}$ \\
\hline 5. & $\begin{array}{l}\text { Определение путей и направлений создания беспилотной авиационной транспортной системы } \\
\text { в соответствии с общими задачами перевозок и их объемами }\end{array}$ \\
\hline 6. & $\begin{array}{l}\text { Обоснование для применения беспилотных аппаратов для решения типовых задач транспортной } \\
\text { компании }\end{array}$ \\
\hline 7. & $\begin{array}{l}\text { Подготовка обоснования структуры и основных характеристик беспилотной авиационной } \\
\text { транспортной системы на базе использования беспилотных аппаратов и эксплуатации беспилотной } \\
\text { авиационной транспортной системы }\end{array}$ \\
\hline 8. & $\begin{array}{l}\text { Определение принципов, в соответствии с которыми будет выстраиваться пространственное } \\
\text { расположение элементов в составе беспилотной авиационной транспортной системы }\end{array}$ \\
\hline 9. & $\begin{array}{l}\text { Моделирование транспортных процессов и определение на этой основе рациональных вариантов } \\
\text { построение беспилотной авиационной транспортной системы }\end{array}$ \\
\hline 10. & $\begin{array}{l}\text { Разработка принципов и конкретных этапов, в соответствии с которыми беспилотная авиационная } \\
\text { транспортная система будет включаться в существующие и появляющиеся в будущем транспортные } \\
\text { системы }\end{array}$ \\
\hline
\end{tabular}

\section{Таблица 2}

\begin{tabular}{|c|c|}
\hline Проблемы в технологиях и науке & $\begin{array}{l}\text { Влияние проблем в технологиях и науке на особенности } \\
\text { жизненного цикла беспилотных авиационных транспортных } \\
\text { систем }\end{array}$ \\
\hline $\begin{array}{l}\text { Низкий уровень эффективности силовых установок } \\
\text { и формообразующих конструкций планера }\end{array}$ & $\begin{array}{l}\text { Зависимость беспилотных аппаратов от погодных условий, } \\
\text { невозможность их использования с применением } \\
\text { альтернативных источников энергии }\end{array}$ \\
\hline $\begin{array}{l}\text { Отставание критических технологий в области в области } \\
\text { сенсоров и технического зрения }\end{array}$ & $\begin{array}{l}\text { Потеря аппаратов из-за сбоев техники и электроники, как } \\
\text { правило, невозможность проведения восстановительного } \\
\text { ремонта }\end{array}$ \\
\hline Проблемы в функционировании систем связи и коммуникаций & $\begin{array}{l}\text { Наличие «слепых» зон лишает возможности оператору } \\
\text { контролировать маршрут полета, а разработчикам и техническим } \\
\text { специалистам — контролировать параметры полета }\end{array}$ \\
\hline $\begin{array}{l}\text { Низкий уровень помехозащищенности и интеллектуализации } \\
\text { беспилотных воздушных судов }\end{array}$ & $\begin{array}{l}\text { Ограничение сферы использования беспилотных аппаратов, } \\
\text { высокие риски утраты аппаратов в ходе выполнения полета, } \\
\text { ограниченный круг задач, которые можно выполнить в рамках } \\
\text { сопровождения полета }\end{array}$ \\
\hline
\end{tabular}


му для управления и развитием транспортной системы. Еще требуется организовать обучение и прохождение сертификации персонала, который будет заниматься вопросами эксплуатации беспилотных аппаратов и наземных средств. [7]

Собственником авиационной беспилотной транспортной системы может быть эксплуатант (действующая компания с лицензией на осуществление полетов), компании со смешанным парком, где представлены беспилотные и пилотируемые воздушные суда, а также специализированные компании, в парке которых представлены только пилотируемые воздушные суда. Беспилотная авиационная транспортная система может взаимодействовать с авиационной транспортной системой, с морской транспортной системой и т.д. При этом создание беспилотной авиационной транспортной системы осуществляется в рамках решения целого ряда научно-исследовательских задач. Все они представлены ниже в таблице 1.

Пока беспилотные авиационные транспортные системы не получили такого широкого распространения и не позволили обеспечить требуемую эффективность от их использования в связи с проблемами на разных этапах жизненного цикла беспилотных авиационных транспортных систем и элементов в их составе. Подробнее эти проблемы и их взаимосвязь с жизненным циклом проанализированы в таблице 2.

Чтобы решить проблемы на разных этапах жизненного цикла беспилотных авиационных транспортных систем, требуется применить комплексный подход. Так как автономность и функционирование беспилотных аппаратов на больших высотах ограничены, требуется проработать на уровне науки вопросы, связанные с увеличением характеристик автономности беспилотных аппаратов, а также вопросы, связанные с их эксплуатацией на больших высотах. В случае с групповым применением беспилотных воздушных судов требуется выработать технические решения, которые позволят поддерживать межсамолетную навигацию. Средства управления и связи для управления беспилотными аппаратами (в том числе, группами беспилотных аппаратов) требуют дора- ботки и рассмотрения возможности применения комбинированных средств управления и связи на основе спутниковой передачи данных, команд через сети мобильной связи и т.д. При автоматическом взлете и посадке беспилотные аппараты часто получают повреждения из-за проблем сенсоров и технического зрения. Следовательно, для автоматизации этих процессов требуется усовершенствовать сенсоры и техническое зрение беспилотных воздушных судов.

Существенной проблемой является уровень помехозащищенности, когда несколько используемых каналов связи приводят к сбоям в информационном обмене. Для решения проблему необходимо усовершенствовать систему кодификации каналов для радиообмена. С учетом высокого уровня киберугрозы требуется предусмотреть эффективные механизмы защиты от посягательств киберпреступников на нормальную работу объектов телекоммуникационной среды. Транспортные процессы с использованием беспилотных воздушных судов пока имеют низкий уровень интеллектуализации. [8]

Следовательно, задача науки сводится к тому, чтобы усовершенствовать применение интеллектуальных технологий при осуществлении транспортных процессов. Возможно, решить эту задачу удастся с применением искусственного интеллекта в организации и сопровождении транспортных процессов. Загрузочно-погрузочные работы, а также зарядка и перезарядка беспилотных воздушных судов сегодня осуществляются при активном участии человека. Эти процессы в перспективе должны быть автоматизированы в том числе за счет использования технологий на основе искусственного интеллекта. Научно-исследовательские центры и конструкторские бюро необходимо подключить к работе, направленной на создание оптимальных вариантов создания и применения беспилотных авиационных транспортных систем с применением современных систем моделирования. Также требуется развивать технологии в области логистических систем управления, наземных систем обнаружения и слежения за беспилотными воздушными судами. Только с решением этих задач можно говорить о перспективном развитии беспилотных авиационных транспортных систем.

\section{ЛИТЕРАТУРА}

1. Агеева Н.Г., Афанасов М. А., Минаев Э.С. Анализ состояния и прогноз развития рынка современных беспилотных авиационных систем // Микроэкономика. 2016. № 1. С. 19-25.

2. Горяшко А. А. Авиапредприятие на рынке международных грузовых авиаперевозок (прогнозирование состояния, принятие управленческих решений): диссертация на соискание ученой степени кандидата технических наук. Москва, 2014. - 172 с.

3. Колосов С.В., Абдуллина А. Б., Шваюк В. Д. Правовые аспекты эксплуатации беспилотных летательных аппаратов // Сборник: Теоретические и методологические проблемы современных наук материалы XVII международной научно-практической конференции. 2016. С. 95-99.

4. Королева Н.В., Левченко А. С. Состояние и перспективы развития рынка беспилотных авиационных систем гражданского назначения // Актуальные научные исследования в современном мире. 2016. № 11-2 (19). С. 77-79. 
5. Королева Н.В., Левченко А. С. Состояние и перспективы развития рынка беспилотных авиационных систем гражданского назначения // Актуальные научные исследования в современном мире. 2016. № 11-2 (19). С. 77-79.

6. Кошкин Р.П. Основные направления развития и совершенствования беспилотных авиационных систем // Научный вестник ГосНИИ ГА. 2015. № 10 (321). C. 16-25.

7. Кошкин Р.П. Проблемы нормативно-правового регулирования применения в воздушном пространстве беспилотных авиационных систем // Научный вестник ГосНИИ ГА. 2015. № 11 (322). С. 23-32.

8. Титков 0. С. Интеграция беспилотных авиационных систем в воздушное пространство // Авиационные системы. 2014. № 9. С. 20-32. Титков 0. С. Интеграция беспилотных авиационных систем в воздушное пространство (продолжение) // Авиационные системы. 2014. № 10. С. 34-50.

9. Худоленко 0. В. Эффективность эксплуатации воздушных судов и совершенствование организации производства при выполнении авиаработ (теория и практика): диссертация на соискание ученой степени доктора технических наук. Москва, 2016. - 352 с.

○ Салахутдинов Ильдар Тагирович ( Eleloy1@gmail.com ).

Журнал «Современная наука: актуальные проблемы теории и практики»

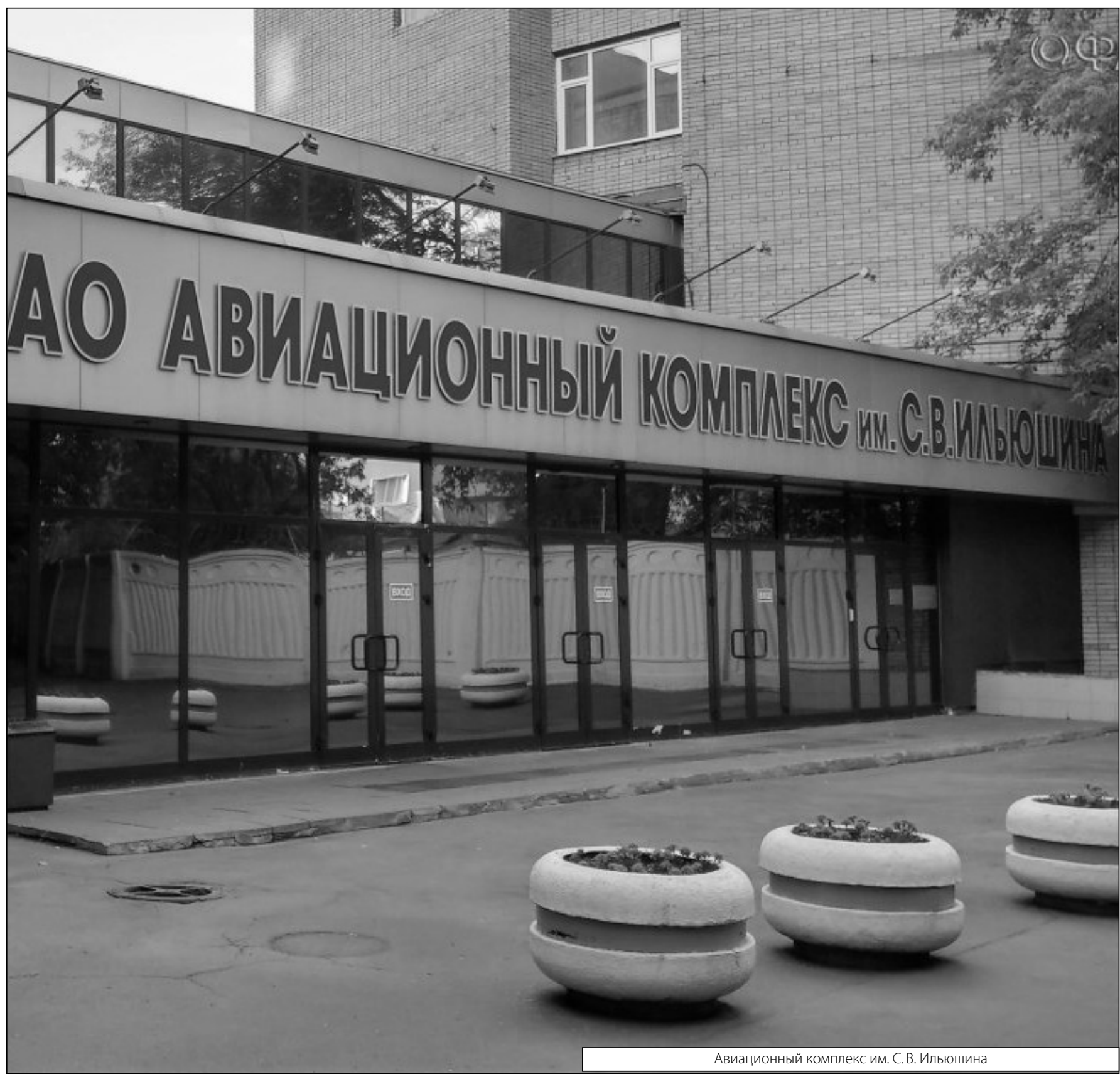

